\title{
LIBERDADE DE EXPRESSÃO E CENSURA JUDICIAL: UMA ANÁLISE DA INTERNET
}

\author{
José Claudio Monteiro de Brito Filho* \\ Peterson Pedro Souza e Sousa*
}

RESUMO: A pesquisa analisou a liberdade de expressão e a censura judicial no contexto inserido pela internet. Por meio do estudo bibliográfico e jurisprudencial, buscou-se definir o conteúdo do direito à liberdade de expressão e o seu exercício através da internet. Em seguida, passou-se a examinar o polêmico Inquérito das "fake news" (4.781 DF), do qual emanaram-se decisões colidentes com as garantias conferidas à liberdade de expressão. Por fim, após a discussão dos resultados, buscou-se evidenciar os perigos da censura judicial nas plataformas virtuais.

PALAVRAS-CHAVE: Liberdade de expressão; internet; censura judicial; fake news; perigos da censura.

\section{FREEDOM OF EXPRESSION AND JUDICIAL CENSORSHIP: AN INTERNET ANALYSIS}

\begin{abstract}
The research sought to analyze freedom of expression and judicial censorship in the context inserted by the internet. Through bibliographic and jurisprudential study, we sought to define the content of the right to freedom of expression and its exercise through the internet. Then, the controversial "fake news" survey (4,781 DF) began to be examined, which resulted in conflicting decisions with the guarantees given to freedom of expression. Finally, after discussing the results, we sought to highlight the dangers of judicial censorship on virtual platforms.
\end{abstract}

KEY-WORDS: Freedom of expression; Internet; judicial censorship; fake news; dangers of censorship.

\section{INTRODUÇÃO}

Após a Constituição da República Federativa do Brasil de 1988, a Lei de Imprensa foi submetia ao escrutínio da Suprema Corte através da Arguição de Preceito Fundamental no 130 DF (doravante, ADPF 130). Em 2009, o Supremo julgou procedente a ação e declarou que a

\footnotetext{
${ }^{*}$ Doutor em Direito pela PUC/SP. Vice-coordenador do PPGD e Editor-chefe da Revista Jurídica do CESUPA. Titular da Cadeira n ${ }^{\circ} 26$ da ABDT. Líder do Grupo de Pesquisa (CNPQ) em Trabalho Decente, do CESUPA. Email: jclaudiobritofilho@gmail.com.

** Advogado (Grupo Liberal), Mestrando em Direito (Programa de Pós-Graduação em Direito, Políticas Públicas e Desenvolvimento (PPGD-CESUPA). Bacharel em Ciências Contábeis (FCAT) E-mail: petersonsousa16@gmail.com.
} 
referida norma (Lei $n^{\circ}$ 5.250/64) é incompatível com a atual ordem constitucional. Na época, contava-se apenas vinte e um anos desde a saída do regime ditatorial, isto é, o receio de censura ainda atormentava os juristas. Assim, optou-se por uma liberdade de expressão e de imprensa desregulamentada.

Desde da ADPF 130, quando se litiga em matéria versando a liberdade de expressão, é de praxe se socorrer ao texto constitucional, local onde nem sempre se encontram as respostas para o caso concreto. Diante da deficiência analítica versando a respeito da temática, a jurisprudência emergiu com soluções para determinadas demandas. Ao lado, a doutrina também se esforçou para apresentar respostas aos hard cases (casos difíceis). No entanto, ainda há uma zona de penumbra.

Com a chegada da era digital, o meio por onde as pessoas passaram a exprimir opiniões mudou consideravelmente. A internet inseriu o indivíduo em um novo ambiente, conferindo maior liberdade e alcance às opiniões proferidas. Antes, a expressão era limitada à um determinado território ou meio de comunicação. No panorama atual, o mundo virtual é veloz e não comporta barreiras geográficas.

$\mathrm{O}$ acesso em massa às tecnologias permitiu um dinamismo informacional maior, assim como, uma amplificação do exercício da liberdade de expressão. No entanto, o cenário digital também apresenta perigos para outros direitos fundamentais. Considerando que a internet é um mundo onde seus habitantes não são facilmente identificados, percebe-se que o ambiente virtual é um terreno fértil para a irresponsabilidade e, consequentemente, de impunidade para aqueles que pretendem extrapolar os limites da liberdade de expressão.

Nesses casos, é comum que alguns ofendidos busquem a tutela dos seus direitos no Judiciário. Todavia, diante do hiato normativo acerca do tema, a solução é, por vezes, sombria. Não é raro observar episódios onde magistrados - em face da ausência de regras disciplinando o assunto - findam buscando amparo em fontes que nem sempre são hábeis para responder a contenda. Quer seja por precedentes, doutrina ou através da própria interpretação linguística da norma constitucional, a solução de um tema importante resume-se, muitas vezes, às convicções do julgador.

Em uma segunda análise, verifica-se que a internet inaugurou um novo ambiente de desafios à liberdade de expressão e à atividade jurisdicional. A inquietação que instigou o estudo consiste na penumbra normativa funcionar com subterfúgio à censura judicial. Amordaçar 
internautas por meio de ordens judiciais com amparo em inclinações pessoais pode ser perigoso não só à liberdade de expressão, como também à própria democracia.

Assim, o presente estudo tem por objetivo examinar a intervenção judicial na internet como ato de censura, ou melhor, considerando a jurisprudência da Suprema Corte brasileira, em que circunstâncias poder-se-ia considerar como legítima a interferência do Estado no exercício da liberdade de expressão em ambiente virtual.

Para abordar o problema será realizada uma pesquisa teórica-normativa, utilizando-se de textos legais, jurisprudência selecionada e a doutrina. Inicialmente, serão feitas algumas considerações sobre a liberdade de expressão no ambiente virtual e, em seguida, pretende-se discutir as limitações, os excessos e a censura através de eventos recentes experimentados pelo Judiciário brasileiro.

No item 2 o estudo dedica-se a abordar a liberdade de expressão no Brasil sob a ótica normativa e doutrinária, bem como, observando as mudanças inseridas com a internet. $\mathrm{O}$ objetivo foi introduzir as noções básicas do direito para conduzir a pesquisa. Assim, utilizou-se das definições lecionadas por Alexandre de Moraes, assim como, de outros expoentes da doutrina constitucional. A pesquisa também contou com as ideias descritas na obra seminal "Sobre a liberdade" do liberal inglês John Stuart Mill.

Em seguida, passou-se a realizar uma análise da evolução jurisprudencial brasileira sobre a liberdade de expressão. Examinou-se alguns julgados do Supremo Tribunal Federal com a finalidade de extrair a compreensão predominante na Corte sobre o tema.

Por último, no item 3, a pesquisa empenhou-se em verificar os excessos, a limitação e a censura judicial. Como objeto de análise, utilizou-se o polêmico Inquérito $\mathrm{n}^{\circ} 4.781 \mathrm{DF}$, do qual emanaram ordens judiciais restringindo a liberdade de expressão exercida na internet.

\section{A LIBERDADE DE EXPRESSÃO NA INTERNERT}

A liberdade de expressão é a mola propulsora de mudanças históricas e avanços civilizatórios. No Brasil, durante o regime militar (1964-1985) o direito foi consideravelmente suprimido na justificativa de proteger a soberania nacional diante de uma ameaça comunista. Outros afirmam que foi um golpe de poder. A história é contada em várias versões. Entretanto, seja qual for o ponto de vista, é inegável que a liberdade de expressão foi restringida durante aquele período. 
Com a redemocratização brasileira, principalmente após a Constituinte que resultou no texto constitucional de 1988, a liberdade de expressão ganhou uma dimensão valorativa maior. A experiência com regime militar rendeu várias reflexões sobre as liberdades. Nesse passo, alguns comportamentos em defesa da expressão - livre da regulação estatal - passaram a ser observados pelos poderes constituídos, principalmente, pela Corte Constitucional.

Antes de analisar alguns julgados sobre o assunto, algumas linhas conceituais sobre o direito em si são necessárias. Normativamente, a liberdade de expressão é consagrada no texto constitucional, assegurando que "é livre a manifestação do pensamento, sendo vedado o anonimato" (BRASIL, 1988, Art. 5 , IV), de igual forma dispõe que "é livre a expressão da atividade intelectual, artística, científica e de comunicação, independentemente de censura ou licença" (BRASIL, 1988, Art. 5º, IX).

Adiante, quando trata da comunicação social, a Carta Magna estabelece que "a manifestação do pensamento, a criação, a expressão e a informação, sob qualquer forma, processo ou veículo não sofrerão qualquer restrição, observado o disposto nesta Constituição" (BRASIL, 1988, Art. 220) e ainda reforça que "é vedada qualquer censura de natureza política, ideológica e artística" (BRASIL, 1988, Art. 220, §2º $)$.

Nessa linha, conforme ensina Moraes (2018, p. 104), pode-se dizer que a liberdade de expressão é protegida em dois ângulos. No primeiro, têm-se a tutela num aspecto positivo, assegurando ao cidadão que se manifeste como bem entender, podendo, no entanto, ser responsabilizado pelo conteúdo difundido. O segundo contempla uma proteção em um sentido negativo, o qual visa impedir a ilegítima intervenção prévia do Estado-Censor no conteúdo a ser expressado.

De forma semelhante, Sarlet, Marinoni e Mitidiero (2019, p. 509) aduzem que a liberdade de expressão abrange tanto o direito (faculdade) de o indivíduo se exprimir quanto o direito de quedar-se inerte e não se expressar ou informar-se. Assim, a primeira proposição assume uma condição de direito negativo, isto é, assegurar exercício da liberdade sem qualquer embaraço. Isso implica, também, em uma certa dimensão positiva, principalmente no sentido de acesso aos meios de expressão.

Com relação ao conteúdo do direito em estudo, Mendes e Branco (2019, p. 394) assinalam que: 
Incluem-se na liberdade de expressão faculdades diversas, como a de comunicação de pensamentos, de ideias, de informações, de críticas, que podem assumir modalidade não verbal (comportamental, musical, por imagem etc.). O grau de proteção que cada uma dessas formas de se exprimir recebe costuma variar, não obstante todas terem amparo na Lei Maior.

Com base nos apontamentos até aqui expostos, nota-se que o ordenamento jurídico brasileiro adotou o pensamento articulado pelo filósofo inglês John Stuart Mill (1859) na obra “Sobre a Liberdade”. Mill (2019, p.22) entendia que a única justificativa legítima para interferir na liberdade individual é a de evitar dano a outra pessoa. Somente essa lógica, denominada de "princípio do dano”, seria capaz de reger as relações da sociedade com o indivíduo.

É digno destacar que, especificamente com relação a liberdade de opinião, o pensador britânico defendia um direito absoluto, mesmo considerando a hipótese de responsabilização ulterior. Não é demais lembrar que em 1859 - ano em que Sobre a Liberdade foi publicado - o mundo já havia experimentado vários episódios de censura, os quais até hoje ilustram boas razões para sustentar a expressão livre ${ }^{1}$. Em defesa da mais ampla liberdade de expressão, Mill (2019) posicionava-se em favor de um ambiente de livre debate, vez que, em sua visão, somente na atmosfera de ampla liberdade a verdade poderia prevalecer.

Retomando à experiência brasileira sobre a liberdade de expressão, registre-se que o exemplo jurisprudencial mais emblemático foi a Arguição de Descumprimento de Preceito Fundamental $n^{\circ} 130$ (ADPF 130 DF), a qual afastou a Lei de Impressa por incompatibilidade com a ordem constitucional.

Não há como negar que o julgamento da ADPF 130 DF estabeleceu novos contornos às liberdades constitucionais, especialmente a de imprensa e a de expressão. Com efeito, influenciada ainda com juvenil ordem democrática pós-ditadura, a composição da Corte, na época do julgamento (2009), contava com juristas que experimentaram a supressão da livre opinião. Nesse contexto, a ADPF 130 DF reconheceu que a regulação da liberdade por meio da Lei de Imprensa é uma limitação per si do direito, configurando uma restrição incompatível com a Constituição Democrática em vigor.

Nesse importante precedente, Supremo foi categórico ao enfatizar a função vital das liberdades à democracia. Observe-se o interessante apontamento feito pelo Ministro Gilmar Mendes no julgado:

\footnotetext{
${ }^{1}$ Mill (2019) cita como exemplo Sócrates que foi acusado de imoral por pensar e expressar-se de forma diferente, sentenciado à morte. Também rememora do julgamento de Jesus Cristo, morto sob a acusação de blasfêmia.
} 
Talvez seja essa uma das mais importantes funções das liberdades de expressão e de impressa na democracia. O livre tráfego de ideias e a diversidade de opiniões são elementos essenciais para o bom funcionamento de um sistema democrático e para a existência de uma sociedade aberta. (BRASIL, STF, 2009)

$\mathrm{Na}$ ocasião, assentou-se a tese de que a liberdade de expressão e de imprensa devem ser livres dos grilhões reguladores estatais. No julgamento ficou muito claro que, nas sábias e pragmáticas palavras do Ministro Menezes Direito, "o preço do silêncio para a saúde institucional dos povos é muito mais alto do que o preço da livre circulação das ideias" (BRASIL, STF, 2009).

Outro julgado simbólico sobre a matéria encontra-se na Ação Direta de Inconstitucionalidade $\mathrm{n}^{\circ}$ 4.815 DF (ADI 4.815 DF). Sob relatoria da Ministra Carmen Lúcia, a Corte entendeu ser desnecessária a autorização prévia para a publicação de biografias. Na oportunidade, o voto vencedor aduziu interessante reflexão, verbis:

Este é um julgamento sobre o direito à palavra e a liberdade de expressá-la. Sem verbo, há o silêncio humano. Às vezes desumano. Por isso, a Constituição da República e todos os textos declaratórios de direitos fundamentais, ou de direitos humanos, garantem como núcleo duro e essencial da vivência humana a comunicação, que se faz essencialmente pela palavra.

No princípio era o Verbo. No Direito, o princípio e os fins definam-se em Verbo.

O sentido, o sabor e o saber da comunicação humana, condutores da história da humanidade - de cada um e de todos -, põem-se na palavra. Palavra é liberdade e convivência para a libertação de pessoas e de povos.

(BRASIL, STF, 2015)

Como se observa, a liberdade deve ocupar uma posição de prestígio na visão da Corte, ou melhor, como apontou o Ministro Luís Roberto Barroso na ADI 4.815 DF, o direito revela uma "primazia prima facie da liberdade de expressão no processo de ponderação. Seu afastamento há de ser a exceção e o ônus argumentativo é de quem sustenta o direito oposto" (BRASIL, 2015).

Em evolução mais recente sobre a temática, o Supremo Tribunal Federal fixou a compreensão de que são inconstitucionais as normas eleitorais que vedavam as sátiras de candidatos. No voto do Ministro Relator Alexandre de Moraes “a democracia não existirá e a livre participação política não florescerá onde a liberdade de expressão for ceifada" (BRASIL, STF, 2019).

Ainda de acordo com o Relator: 
O funcionamento eficaz da democracia representativa exige absoluto respeito à ampla liberdade de expressão, possibilitando a liberdade de opinião, de criação artística, a proliferação de informações, a circulação de ideias; garantindo-se, portanto, os diversos e antagônicos discursos - moralistas e obscenos, conservadores e progressistas, científicos, literários, jornalísticos ou humorísticos, pois, no dizer de HEGEL, é no espaço público de discussão que a verdade e a falsidade coabitam.

(BRASIL, STF, 2019)

À luz da jurisprudência colacionada, verifica-se que o laconismo normativo sobre a liberdade de expressão coloca em penumbra os contornos do direito. A circunstância torna-se mais evidente quando ao constatar que o conflito sobre a matéria é submetido com frequência ao Judiciário.

Assim, como gizado acima, cabe aos juízes, utilizando-se de critérios de ponderação em contendas específicas, delinear os limites do direito fundamental. Logo, percebe-se que uma questão de grande magnitude social é delimitada através da caneta de togados que não foram eleitos pelo povo por meio de julgamentos que, por vezes, podem traduzir inclinações pessoais.

Em uma segunda análise, não restam dúvidas que a internet também pode ser considerada como um meio ambiente por meio do qual o direito é exercido. Com razão, o avanço da tecnologia permitiu que o direito à liberdade de expressão se tornasse mais concretizável para os cidadãos. Isso porque antes, a opinião pessoal, por exemplo, cingia-se às fronteiras do meio utilizado para expressar-se. No Brasil, o monopólio dos tradicionais veículos de comunicação (jornais, televisões e rádios) afunilou, por anos, o acesso à liberdade, ao menos num aspecto instrumental.

Diz-se instrumental, pois, a liberdade de expressão, conforme Machado (2002, apud Maiorana 2019, p. 89), deve ser compreendida em duas dimensões:

Nesse sentido, deve-se sublinhar a dupla dimensão deste direito. A dimensão substantiva compreende a atividade de pensar, formar a própria opinião e exterioriza-la. A dimensão instrumental traduz a possibilidade de utilizar os mais diversos meios adequados à divulgação do pensamento.

Dessa maneira, conclui-se que o ambiente virtual provocou uma verdadeira ruptura nas barreiras instrumentais da expressão. Um novo mundo, onde vigora a livre comunicação, tornouse realidade. Portanto, atualmente se pode visualizar uma dimensão instrumental nova para o direito: a internet. Cuida-se de um meio - consideravelmente mais livre e mais acessível - por onde as pessoas se expressam. 
O raciocínio de uma liberdade factível em ambas dimensões pode ser extraído, por exemplo, das declarações políticas e normas internacionais. Observe-se que a Declaração Universal de Direitos Humanos (DUDH), afirma que toda pessoa direito à liberdade de expressar-se sem interferência, isso envolve opinar, procurar, receber e transmitir informações e ideias por quaisquer meios (ONU, 1948, Artigo 19). No mesmo sentido, soa o Pacto Internacional de Direitos Civis e Políticos (Decreto no 592/1992) quando aduz que "ninguém poderá ser molestado por suas opiniões" e que a liberdade de expressão abrange o direito de "procurar, receber e difundir informações e ideias", independentemente de fronteiras (BRASIL, 1992, Art. 19).

Ainda no plano internacional, a Convenção Americana sobre Direitos Humanos (Decreto $n^{\circ}$ 678/1992) prevê o mesmo direito e assegura que o exercício do direito à liberdade de expressão não pode estar sujeito à censura prévia, no entanto, é submetido a responsabilidades ulteriores (BRASIL, 1992, Art. 13, Inc. 1).

Ao cotejar as normas internacionais retromencionadas com a realidade inserida com o advento da internet, é possível vislumbrar contornos de um novo espaço onde a liberdade é exercida. Assim, é possível inferir que o acesso à internet pode até ser tratado como um direito humano.

À propósito, Eduardo Magrani (2014) em sua obra Democracia Conectada comenta que em maio de 2011, o Special Rapporteur da ONU, Frank La Rue, pleiteou o reconhecimento do acesso à internet como direito humano, considerando-o como um dos principais meios pelo qual os indivíduos podem exercer seu direito à liberdade de expressão. Na tradução de Magrini (2014, p. 20-21), La Rue recomendou:

Diferentemente de qualquer outro meio, a internet possibilita que os indivíduos procurem, recebam e transmitam informações e ideias de toda sorte, instantânea e gratuitamente, cruzando fronteiras nacionais. Ao expandir vastamente a capacidade das pessoas de exercitarem seu direito à liberdade de opinião e de expressão - promotor, por excelência, de outros direitos -, a internet gera avanços no campo do desenvolvimento econômico, social e político, assim como contribui para o progresso da humanidade como um todo. (...) Dado que a internet se tornou uma ferramenta indispensável para a realização de um sem número de direitos humanos, para o combate da desigualdade e para a aceleração do desenvolvimento e do progresso humanos, assegurar um acesso universal à internet deveria ser prioridade de todos os Estados. 
No plano das normas domésticas, o Marco Civil da internet (Lei 12.965/2014), por mais que tardio às mudanças já experimentadas, inaugurou um novo panorama jurídico ao espaço virtual de comunicação. Nessa vereda, reconheceu expressamente que o "uso da internet no Brasil tem como fundamento o respeito à liberdade de expressão" (BRASIL, 2014, Art. $2^{\circ}$ ).

Com o avanço tecnológico, o ambiente informacional mudou completamente. Uma tendência de descentralização dos antigos monopólios da comunicação passou a ser observada e não há como negar o que tal fenômeno é salutar para o amadurecimento da democracia.

Frise-se que o acesso à informação é um elemento basilar para o exercício da liberdade de escolha. O acesso a variadas fontes de informações promove tanto a sobrevivência da verdade quanto torna menos provável a demagogia.

Nesse sentido é que Mill (2019) defende que a busca da verdade, livre do despotismo, só é possível em uma atmosfera de irrestrita liberdade de expressão. A desimpedida circulação de opiniões é vital à verdade e, consequentemente, à democracia. Toda tentativa de impor algo como verdade - quer seja pelo costume, quer seja por meio da lei - por mais que o seja, esmaga a individualidade do ser humano, impedindo-o de desenvolver a sua natureza com liberdade.

Ainda a esse respeito, Mill (2019, p. 75-76) enfatiza que:

No atual estado do intelecto humano, é apenas com a diversidade de opiniões que existe a possibilidade de um jogo leal envolvendo todos os lados da verdade. Quando se encontram pessoas que formam exceção à aparente unanimidade do mundo sobre um assunto qualquer, mesmo que o mundo esteja certo, é sempre provável que os discordantes tenham algo a dizer que merece ser ouvido, e o silêncio deles resultaria em alguma perda para a verdade.

Todavia, o progresso decorrente do acesso em massa das redes de internet fez surgir novos desafios. Primeiro, por ser um protocolo virtual de comunicação mundial, a identificação do internauta que divulga uma fake news (notícia falsa), por exemplo, não é tarefa fácil para as autoridades. A dificuldade propicia um terreno fértil para o divulgador não ter compromisso com relação ao conteúdo que publica. Segundo, o cenário virtual permite a criação de falsos perfis, onde o falsário se passa por pessoas que emitem opiniões e críticas, tudo na intenção de convencer o navegante sobre determinada matéria.

Com efeito, não há como negar que a expressão passou a ser exercida por outro espaço, devendo, portanto, ser assegurada a sua tutela na mesma proporção que qualquer outro meio de comunicação. De outro lado, embora os perigos expostos acima, sobressai que a internet promoveu uma amplificação à liberdade de expressão. 


\section{LIMITAÇÕES, EXCESSOS E CENSURA JUDICIAL}

A liberdade de consciência costuma ser definida como um gênero das demais liberdades. Também é oportuno ressaltar, a relação entre as liberdades e a democracia. Os rumos da opinião pública são guiados pelos ventos da informação e da expressão, por isso justifica-se a livre circulação de ideias como forma liberdade. Entretanto, deve-se destacar que não se trata de um direito absoluto. $\mathrm{Na}$ atual ordem constitucional, é necessário harmonizar a liberdade de expressão com os demais direitos fundamentais e isso, por vezes, pode exigir certas restrições.

Quando se fala em contornos à liberdade de expressão busca-se definir o direito abstrato para solucionar casos concretos. Após a ADPF 130 DF, a qual afastou a Lei de Imprensa, as fronteiras expressas à liberdade foram soterradas. O julgamento histórico, exigiu uma redefinição do conteúdo do direito à luz da ordem constitucional vigente.

Desde então, ampliou-se a discricionariedade dos magistrados para julgar o caso concreto, avaliando se houve ou não excesso no exercício da liberdade capaz de legitimar uma intervenção jurisdicional. Acontece que recorrer a enunciados abstratos - na hipótese, à norma constitucional - possibilita certos perigos, como por exemplo, valer-se o juiz de um interpretativismo sem muito compromisso com o direito.

Nesse contexto, insere-se o ativismo judicial que sinteticamente pode ser compreendido como o fenômeno de expansão do Poder Judiciário revelado em decisões que, em tese, caberiam a outros poderes. Tal avanço, trouxe consigo defensores e críticos.

Barroso (2013), por exemplo, defende o fenômeno entendendo se tratar de um exercício legítimo da atividade jurisdicional, por meio da qual se procura extrair "o máximo de potencialidades do texto constitucional, inclusive e especialmente construindo regras específicas de conduta a partir de enunciados vagos (princípios, conceitos jurídicos indeterminados) " (BARROSO, 2013).

Por outro lado, Sarmento (2009, p. 43-45) posiciona-se com certa preocupação a respeito do fenômeno, principalmente no que concerne a previsibilidade e segurança jurídica. De acordo com autor, o ativismo pode ser galgado por uma metodologia jurídica emotiva com tendência de invocação frouxa e não fundamentada de princípios. Sarmento (2009) tem razão, vez que a expansão jurisdicional é capaz de aradar um espaço onde o arbítrio pode ser facilmente germinado. 
Realmente, a textura aberta da norma constitucional sobre liberdade de expressão é uma clara demonstração do receio apontado por Sarmento (2009). A redação do art. $5^{\circ}$ e do art. 220 da Constituição da República permite várias interpretações sobre o assunto e isso promove, inevitavelmente, uma situação de instabilidade.

A questão é bem relatada por Leite (2014, apud Mello, 2019, p. 43):

O problema da liberdade de expressão no Brasil talvez seja a ideia de que não há propriamente um problema a ser resolvido. Afinal, trata-se de um direito (essencial à democracia) que foi restabelecido pela Constituição de 1988, que, de forma categórica, baniu a censura do ordenamento jurídico do País (arts. $5^{\circ}$, IX, e $220, \S 2^{\circ}$ ). Esta garantia, contudo, limita-se a proibir restrições (a priori ou a posteriori) impostas pelos órgãos de governo - sem dúvida um grande passo, se considerarmos a experiência vivenciada sob o regime constitucional anterior, mas que nada (ou muito pouco) diz a respeito do "conteúdo" protegido pela liberdade de expressão, livre de qualquer espécie de condenação pelo poder público. Em outras palavras: há uma garantia de que um discurso não será proibido pelo governo, mas nenhuma garantia de que não será condenado pelo Poder Judiciário.

Levando ao contexto da internet, é preciso considerar que com a chegada da era digital o direito à liberdade de expressão tornou-se mais concretizável do ponto de vista instrumental. No entanto, o avanço tecnológico lançou desafios às autoridades, principalmente ao Judiciário, com relação a colisão com os demais direitos fundamentais.

O exemplo mais recente do Supremo Tribunal Federal consiste no polêmico Inquérito $\mathrm{n}^{\mathrm{o}}$ 4.781 DF que apura, segundo o Relator Ministro Alexandre de Moraes, fake news, falsa comunicações de crimes, denunciações caluniosas, ameaças e infrações contra a honra e segurança do STF.

Na investigação, o Ministro determinou, em decisão monocrática, o bloqueio de contas em redes sociais por entender necessário para a interrupção dos discursos com conteúdo de ódio, subversão da ordem e incentivo à quebra da normalidade institucional e democrática.

Analisando detidamente a providência singular, verifica-se que a ordem atinge pessoas, aparentemente, ligadas ao Senhor Presidente da República Jair Messias Bolsonaro, por emanarem críticas, opiniões políticas e palavras chulas contra o Supremo e seus Ministros. No entendimento do Relator:

Como se vê de tudo até então apresentado, recaem sobre os indivíduos aqui identificados sérias suspeitas de que integrariam esse complexo esquema de disseminação de notícias falsas por intermédio de publicações em redes sociais, atingindo um público diário de milhões de pessoas, expondo a perigo de lesão, 
com suas notícias ofensivas e fraudulentas, a independência dos poderes e o Estado de Direito. (BRASIL, STF, 2020).

Conforme se depreende da decisão, o Ministro Alexandre de Moraes apoiou-se em um relatório técnico pericial onde evidenciou que, onze perfis da rede social twitter, publicaram entre 07/11/2019 e 19/11/2019 pelo menos um dos seguintes termos, ipsis litteris: “\#impeachmentgilmarmendes, \#Hienasdetoga, \#forastf, \#lavatoga, STF, SUPREMO, IMPEACHMENT, toffoli ou Gilmar" (BRASIL, STF, 2020).

Talvez a Suprema Corte brasileira esteja atravessando um período de descrédito em razão de decisões tão contraditórias em um curto espaço de tempo. $\mathrm{O}$ cidadão, ainda que pouco politizado ou instruído, observa com ceticismo o comportamento da Corte e, naturalmente, emite críticas. Mesmo considerando os fundamentos da decisão em análise, não há como afastar a falta de congruência com a jurisprudência da própria Corte sobre o assunto.

Do ponto de vista da liberdade de expressão, observa-se a disparidade conceitual manejada pelo Supremo, pois em julgados anteriores, inclusive sob Relatoria do Ministro Alexandre de Moraes, o entendimento em defesa da liberdade abrangeria também "os diversos e antagônicos discursos - moralistas e obscenos, conservadores e progressistas" (BRASIL, STF, 2019).

Ademais, no Inquérito $\mathrm{n}^{\circ} 4.781 \mathrm{DF}$, o Relator anunciou que, diante das provas até aquele momento colhidas, verificava-se:

\footnotetext{
A real possibilidade de existência de uma associação criminosa, denominada nos depoimentos dos parlamentares como "Gabinete do Ódio", dedicada a disseminação de notícias falsas, ataques ofensivos a diversas pessoas, às autoridades e às Instituições, dentre elas o Supremo Tribunal Federal, com flagrante conteúdo de ódio, subversão da ordem e incentivo à quebra da normalidade institucional e democrática. (BRASIL, STF, 2020)
}

Por último, o Relator sustentou que os investigados são suspeitos de integrar um esquema de disseminação de notícias falsas nas redes sociais que alcança milhões de pessoas, expondo a perigo de lesão a independência dos poderes e o Estado de Direito (BRASIL, STF, 2020).

Causa perplexidade à história da jurisprudência brasileira que opiniões, verdadeiras ou fraudulentas, legitimem o Estado a impor restrições à liberdade de expressão. Isso é censura. Não se está sustentando a falta de responsabilização do indivíduo que causa danos à terceiros em seus 
atos. A liberdade de expressão, na forma estabelecida em vários julgamentos da Corte, comporta a manifestação de ideia, pensamentos, opiniões, mesmo que contrárias ao que julgam certo.

Rememora-se que a inconstitucionalidade da Lei de Imprensa, por meio do julgamento da ADPF 130 DF, foi um marco histórico à liberdade de expressão, principalmente, pela defesa aguerrida da Corte em favor da livre circulação de opiniões como elemento vital à democracia.

Atualmente, nota-se que a posição do Ministro Relator do Inquérito $\mathrm{n}^{\mathrm{o}} 4.781 \mathrm{DF}$ representa um verdadeiro retrocesso ao avanço democrático, especialmente do ponto de vista da liberdade de expressão. Atuar como órgão inquisidor e censor, determinando a apreensão de a aparelhos dos investigados, bem como, ordenando o bloqueio de contas nas plataformas sociais (facebook, twitter e instagram), pelos motivos exarados na decisão, rememoram um tempo não tão distante da Constituição de 1988.

Os censurados no Inquérito $\mathrm{n}^{\circ} 4.781 \mathrm{DF}$, em sua grande maioria, emitiram opiniões políticas (como a defesa de ditaduras ou impeachment de Ministro), críticas aguçadas ao ativismo judicial e algumas até ofensivas à Suprema Corte e seus Ministros. Porém, nenhuma expressão, entre as elencadas na decisão singular, justifica o amordaçamento dos investigados.

Ainda que a associação de pessoas disseminando opiniões de conteúdo desagradável na internet promova certo perigo a independência dos poderes e ao Estado de Direito, questiona-se: qual dano efetivo aos outros foi causado? Nenhum. Constata-se apenas um receio carregado de subjetividade.

É contraproducente utilizar-se, como argumento, da defesa da independência dos poderes quando a própria Corte, não raramente, assume um ativismo usurpador de funções típicas do Legislativo e do Executivo. De igual forma, é honesto considerar que pensamento anarquista, presente na opinião de alguns censurados, é consequência do descrédito no sistema jurídico, o qual estão subordinados.

Nesse cenário de mudanças sociais e tecnológicas, naturalmente o cidadão manifesta-se conforme sua compreensão. A grande diferença é que a opinião não se limita mais às umbreiras de seu lar ou ao ciclo de amigos. Com o advento da internet como canal de comunicação, a expressão individual emitida passou a ter o mundo como receptor da opinião e isso é saudável à democracia.

Parece que as principais teses, até então, firmadas pela Corte sobre o direito fundamental à liberdade de expressão foram superadas a olho nu, sem o esforço argumentativo 
de quem sustenta o direito oposto. Uma ruptura de tal magnitude jurisprudencial revela um tratamento assimétrico fundamentado em princípios vagos e com uma certa carga de emotividade. Assim, pode-se concluir que a posição adotada no inquérito 4.781 configura uma censura judicial.

\section{CONCLUSÃO}

$\mathrm{O}$ artigo se dedicou a analisar, através da pesquisa bibliográfica e jurisprudencial, as principais ideias sobre liberdade de expressão e o seu exercício na internet para estabelecer os contornos que justificam as restrições ao direito. Utilizou-se as decisões paradigmáticas do Supremo Tribunal Federal, após a Constituição Federal de 1988, para analisar o tratamento da matéria. Por último, confrontou-se os contornos da liberdade de expressão pacificado com a decisão proferida nos autos do inquérito $4.781 \mathrm{DF}$, com intuito de verificar a existência ou não de censura judicial.

Os resultados apontaram que, de fato, a internet é um meio de comunicação por onde a liberdade de expressão é exercida. Observou-se que, desde a chegada da era digital, a manifestação da opinião tornou-se um direito com maior alcance e concretização. Verificou-se que é possível uma defesa do acesso à internet como um direito humano, pois, trata-se de um ambiente onde as liberdades essenciais à democracia são exercidas.

Após as delimitações conceituais, avaliou-se a rápida mudança de interpretação sobre as garantias da liberdade de expressão por base na decisão proferida nos autos do inquérito 4.781 DF, onde se determinou a remoção de conteúdo das redes sociais, bem como, o impedimento de acesso à determinados indivíduos à plataforma de comunicação. Conclui-se que, na esteira do entendimento firmado na jurisprudência da Corte, a decisão evidencia uma censura judicial.

O desfecho do estudo, revela — em uma amostragem da liberdade de expressão — que a expansão do ativismo judicial confere poderes, por vezes ilimitados, aos julgadores que podem valer-se de conceitos abstratos e vagos para, mediante um interpretativismo, romper com conquistas sociais e caras à democracia.

Como foi explanado, a liberdade de expressão não é um direito absoluto. A ordem constitucional vigente exige a harmonia dos direitos fundamentais e em situações de colisão no caso concreto. Para tanto, utiliza-se critérios de ponderação na intenção da decisão judicial não configurar aniquilação dos direitos em questão.

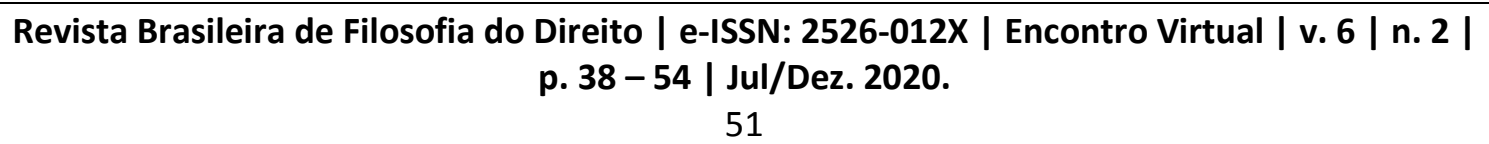


Tratando-se de liberdade de expressão, têm-se observado que a Suprema Corte adotou uma posição de preferência à liberdade, quando conflitante com outros direitos fundamentais. $\mathrm{O}$ raciocínio se sustenta na acentuada importância que a liberdade de expressão guarda com a democracia, devendo, portanto, optar-se por uma restrição somente em casos remotos.

De outro lado, constatou-se que a liberdade de expressão desregulamentada e sem censura prévia é a forma mais adequada de lidar, normativamente, com o direito. Não obstante a isso, o estudo revelou que tal preceito tem sido violado por aqueles que até pouco tempo o defendiam com empenho. O pior é que, na atual conjuntura política brasileira, contra a tirania da opinião judicial não se vislumbra um remédio democrático.

\section{REFERÊNCIAS}

BARROSO, Luis Roberto. Constituição, democracia e supremacia judicial: direito política no Brasil Contemporâneo. As novas faces do ativismo judicial. São Paulo: Saraiva, 2013.

BRASIL, SUPREMO TRIBUNAL FEDERAL (STF). Arguição de Descumprimento de Preceito Fundamental no 130/DF (ADPF 130/DF). Min Rel. Carlos Ayres Britto. Brasília: DJ 30/04/2009. Disponível em:

http://redir.stf.jus.br/paginadorpub/paginador.jsp?docTP=AC\&docID=605411. Acesso em: 01 ago. 2020.

. Ação Direta de Inconstitucionalidade no 4.815 DF (ADI 4.815/DF), Pleno, Min. Rel. Carmém Lúcia. Brasília: DJe 25.06.2015. Disponível em: http://redir.stf.jus.br/paginadorpub/paginador.jsp?docTP=TP\&docID=10162709. Acesso em: 01 ago. 2020.

Ação Direta de Inconstitucionalidade no 4.451/DF (ADIn no 4.451/DF), Pleno, Rel. Min. Alexandre de Moraes. Brasília. Plenário 21/06/2018. DJe 01/03/2019. Disponível em: 
http://portal.stf.jus.br/processos/downloadPeca.asp?id=15339639568\&ext=.pdf. Acesso em 01 ago. 2020.

Inquérito no 4.781 DF. Relator Ministro Alexandre de Moraes. Brasília: 2020. Disponível: http://www.stf.jus.br/arquivo/cms/noticiaNoticiaStf/anexo/mandado27maio.pdf. Acesso em: 01 ago. 2020.

BRASIL. Constituição da República Federativa do Brasil de 1988. Brasília, DF. 5 de outubro de 1988. Disponível em: http://www.planalto.gov.br/ccivil_03/constituicao/constituicao.htm. Acesso em: 20 jul. 2020.

Presidência da República. Casa Civil. Lei 12.965 de 2014. Brasília, DF. 24 de abril de 2014. Disponível em: http://www.planalto.gov.br/ccivil_03/_ato20112014/2014/lei/112965.htm. Acesso em: 01 ago. 2020.

Presidência da República. Casa Civil. Decreto no 592 de 1992. Brasília, DF. 7 de setembro de 1992. Disponível em: http://www.planalto.gov.br/ccivil_03/decreto/19901994/D0592.htm. Acesso em: 01 ago. 2020.

Vice-Presidência da República. Casa Civil. Decreto no 678 de 1992. Brasília, DF. 09 de novembro de 1992. Disponível em: http://www.planalto.gov.br/ccivil_03/decreto/d0678.htm. Acesso em: 01 ago. 2020.

Presidência da República. Casa Civil. Lei 5.250 de 1967 (Lei de Imprensa). Brasília, DF. 02 de fevereiro de 1967. Disponível em:

http://www.planalto.gov.br/ccivil_03/leis/15250.htm. Acesso em: 20 jul. 2020.

MAIORANA, Ronaldo. Direito de Privacidade x Direito à Liberdade de Expressão: Uma análise de Direitos Fundamentais. São Paulo: Editora Nelpa, 2019.

MAGRINI, Eduardo. Democracia conectada: a internet como ferramenta de engajamento político-democrático. Curitiba: Juará, 2014.

MELLO, Rodrigo Gaspar. Liberdade de expressão, honra e censura judicial: uma defesa da incorporação da doutrina da malícia real ao direito brasileiro. Rio de Janeiro: Lumen Juris, 2019.

MENDES, Gilmar Ferreira; BRANCO, Paulo Gustavo Gonet. Curso de direito constitucional. 14. Ed. Rev. e Atual. São Paulo: Saraiva, 2019.

MILL, John Stuart. Sobre a liberdade. Tradução: Denise Bottmann. Porto Alegre, RS: L\&PM, 2019.

MORAES, Alexandre de. A Constituição da República segundo Ministros, Juízes auxiliares e Assessores do STF. Coord. FUX, Luiz; BODART, Bruno e MELLO, Fernando Pessôa da Silveira. Salvador: Editora JusPodivm, 2018. 
SARMENTO. Daniel. O neoconstitucionalismo no Brasil: riscos e possibilidades. Direitos fundamentais e estado constitucional. George Salomão Leite e Ingo Wolfang Sarlet (coords). São Paulo: RT, 2009.

SARLET, Ingo Wolfgang; MARINONI, Luiz Guilherme; MITIDIERO, Daniel. Curso de direito constitucional. $8^{\mathrm{a}}$ ed. São Paulo: Saraiva, 2019.

ORGANIZAÇÃO DAS NAÇÕES UNIDAS (ONU). Declaração Universal dos Direitos Humanos. Paris: 10 dezembro de 1948. Disponível em: https://nacoesunidas.org/wpcontent/uploads/2018/10/DUDH.pdf. Acesso em: 01 ago. 2020. 